\section{IJ§ER}

ISSN: 2149-5939
International Journal of Social Sciences and Education Research

Online, http://dergipark.gov.tr/ijsser

Volume: 3(3), 2017

\title{
Another benefit of mindfulness: Ethical behaviour
}

Yaprak Kalafatoğlu ${ }^{1}$
Tülay Turgut ${ }^{2}$

\begin{abstract}
Received Date: $01 / 02$ / 2017
Accepted Date: 29 / 05 / 2017

Abstract

Severe ethical lapses have damaged the reputation of established corporations in the last decade worldwide. This study aims to investigate the relationship between mindfulness and ethical behaviour. Mindfulness refers to being here and now. Freiburg Mindfulness Inventory was translated into Turkish and used for measuring mindfulness. Ethical Behaviour was assessed with Ethical Behaviour Rating Scale. Data were gathered from 250 white collar employees working in Istanbul. Results indicate that mindfulness has significant relationships with ethical behaviour. This study provides a unique theoretical contribution by examining the link between mindfulness and ethical behaviour among white collar employees. Since mindfulness is a skill, cultivating employee's mindfulness through training programs is among the practical suggestions.
\end{abstract}

Keywords: Mindfulness, Ethical Behaviour, Acceptance, Awareness, Moral life.

\section{Introduction}

Mindfulness refers to being here and now, emotionally and intellectually. The term has originated from Buddhism. However, it has been secularized in the last fifty years and draws the researcher's attention which results with lots of research.

One of the first researchers who examine mindfulness in a scientific way is Kabat-Zinn (1990). He defined mindfulness as "a particular way of paying attention. It is a way of looking deeply into oneself in the spirit of self-inquiry and self-understanding" (Kabat-Zinn, 2005, p.12). According to Kabat-Zinn (2005) mindfulness generates a moral life since mindful mind and heart contains such qualities as generosity, trustworthiness, kindness, empathy, compassion, gratitude, joy in the good fortune of others, inclusiveness, acceptance, and equanimity (p.103). However, the popularity brings a disadvantage; a misuse of the concept which Purser and Loy (2013) defines as "McMindfulness" (Hyland, 2015). It refers to ignoring the ethical basis of mindfulness and benefit from it for the sake of some fields such as military (as improving soldier's attention) or capitalist welfare (increasing productivity). It would be more appropriate to do mindfulness studies without moving away from its core meaning. The aim of the study is bridging this gap by investigating the relationship between mindfulness and ethical behaviour.

\section{Literature review}

Jankowski and Holas (2014) claimed that two orientations exist for interpreting mindfulness: clinical psychology approach and self-determination approach. Kabat-Zinn who is the pioneer of

\footnotetext{
${ }^{1}$ Research Assistant, Marmara University Department of Business Administration, Sub-department of Organizational Behaviour, İstanbul/TURKEY, yaprak.kalafatoglu@marmara.edu.tr

${ }^{2}$ Associate Professor, Marmara University Department of Business Administration, Sub-department of Organizational Behaviour, İstanbul/TURKEY, tturgut@marmara.edu.tr
} 
Kalafatoğlu, Y., Turgut, T. (2017). Another benefit of mindfulness: Ethical behaviour. International Journal of Social Sciences and Education Research, 3(3), 772-782.

the clinical psychology approach, developed Mindfulness Based Stress Reduction Program (MBSR) to treat stress-related physical and psychological problems. Clinical psychology approach handles mindfulness as a skill that can be developed with a practice on meditation. State mindfulness is a term that is utilized for referring clinical psychology approach. On the other hand, in Self Determination Approach (Brown \& Ryan, 2003) mindfulness is defined as "an open or receptive awareness and attention which may be reflected in a more regular of sustained consciousness or ongoing events and experiences" (p.822). Although two approaches are similar in terms of their emphasis on awareness and attention, Brown and Ryan (2003) suggest that mindfulness enhances well-being by saturating autonomy, competence and relatedness needs. Mindfulness is seen as a trait that may occur naturally when a task is done with curiosity and intrinsic motivation. Trait mindfulness is used to define self-determination approach. This study embraces trait approach of mindfulness.

Mindfulness catches the attention of researchers from different disciplines such as clinical psychology and social psychology. Mindfulness was found beneficial in terms of sleep quality and sleep duration (Hülsheger et al., 2014) and cognition (Zeidan et al., 2010). Significant relationships were found between mindfulness and self-control (Wittmann et al., 2014) and self-compassion (Hollis-Walker \& Colosimo, 2011). In organizational psychology research, significant relationships were found between mindfulness and emotion regulation, emotional exhaustion and job satisfaction (Hülsheger, Alberts, Feinholdt \& Lang, 2013), vitality, sleep quality and workfamily balance (Allen \& Kiburz, 2012), and safety behaviour (Zhang \& Wu, 2014). Mindfulness was found negatively associated with deviance and emotional exhaustion (Reb, Narayanan, \& Ho, 2015).

Mindfulness is expected to be related also to ethical behaviour. As stated by Kabat-Zinn mindfulness directs individuals to a moral life as the term is based on a philosophy which governs individuals to be sensitive to others who avoid ignorance. Mindfulness may be positively related with ethical behaviour as it influences the way individuals perceive themselves. With an experimental manipulation, Ruedy and Schweitzer (2010) found that cheating didn't differ between individuals with low and high mindfulness levels but the amount of cheating did. In other words, mindful individuals cheated less than mindless ones. The authors argue that mindfulness leads individuals to be more sensitive related to their self-concept in terms of ethical behaviour. Few amounts of unethical behaviour may be tolerated by them if it doesn't threaten their self-concept.

Mindfulness may also improve ethical decision making. Shapiro, Jazaieri, and Goldin (2012) claimed that it promotes individuals to embrace a more objective point of view instead of a subjective perspective.

Previous research showed that ego depletion results with more unethical behaviour (Mead et al., 2009). Ego depletion is "a state in which the self does not have all the resources it has normally" (Baumeister \& Vohs, 2007, p.2) which result with performance decline in a subsequent task. Yam, Chen and Reynolds (2014) found that social consensus moderates the relationship between ego depletion and unethical behaviour; ego depletion end up with more unethical behaviour of lower social consensus (behaviours that involve more disagreement about its unethicality), but less unethical behaviour of higher social consensus (behaviours that everyone generally agrees are unethical). The authors suggest that depletion has a larger effect on automatic (unethical behaviour of lower social consensus) than controlled behaviour (unethical behaviour of high social consensus). Since mindfulness prevents automatic behaviour and associated with self-control 
Kalafatoğlu, Y., Turgut, T. (2017). Another benefit of mindfulness: Ethical behaviour. International Journal of Social Sciences and Education Research, 3(3), 772-782.

(Brown, Ryan, \& Creswell, 2007; Lakey et al., 2007) it may, directly and indirectly, prevent ego depletion which ends up with more ethical behaviour.

Lastly, mindfulness may compensate the effects of cognitive complexity on moral choices as it improves self-regulation (Bishop et al., 2004), awareness and attention (Vallabh \& Singhal, 2014) which prevents selfish interests.

In conclusion, mindfulness may lead individuals to be sensitive about their self-concept, provide an objective point of view and prevent the negative effects of ego depletion. Besides, it may develop moral reasoning and balance cognitive complexity. These associations may generate more ethical behaviour. Therefore, the aim of the study is to test whether mindfulness predicts ethical behaviour.

H1: Mindfulness contributes positively to ethical behaviour.

\section{Method}

\subsection{Participants and procedure}

The sample $(\mathrm{N}=250)$ consists of white collar employees working in the service sector in İstanbul. Participants are composed of employees aged between 21 and 58 (55.2\% was female, $38 \%$ was male).

Data were gathered through convenience sampling method in three ways. First, an online survey was prepared. It was sent to employees and also shared in a professional network. Second, a number of companies were selected and surveys were sent. Access to the companies was reached through personal contacts. Lastly, surveys were distributed in evening MBA programs with a permission of the lecturer. After they finished, they were thanked, debriefed and the surveys were collected. Data were collected in eight weeks.

\subsection{Scales of measurement}

\section{Mindfulness}

Freiburg Mindfulness Inventory (FMI) was used which is developed by Walach, Buchheld, Buttenmuller, Kleinknecht and Schmidt (2006). The original FMI (Buchheld, Grossman, \& Walach, 2001) has 30 items and it measures mindfulness levels of individuals with meditation practice. Walach et al. (2006) revised it to 16 items-format for assessing mindfulness levels of population with no meditation experience. Walach et al. (2006) proposed that the construct of the scale is one-dimensional. Turkish translation of the scale was applied by the authors and controlled by a group of academicians with mindfulness knowledge. The six-point scale was utilized ranging from 1 (never) to 6 (always). Cronbach alpha value of the scale is .86.

\section{Ethical behaviour}

Ethical Behaviour Rating Scale (Blasi, 1980; Hogan, 1973) has 15 items and the items measure fairness, right and wrong judgment, group allegiance, decentred logic, trustworthiness, loyalty, honesty, empathy, helpfulness, contrition, participation, independence, altruism, cooperation, and respectfulness (Hill \& Swanson, 1985). The six-point scale was used ranging from 1 (never) to 6 (always). Translation of the scale into Turkish was applied by Kapıkıran (2007) and determined as a valid and reliable instrument. Minor change was done in item 10 for converting the scale in 
Kalafatoğlu, Y., Turgut, T. (2017). Another benefit of mindfulness: Ethical behaviour. International Journal of Social Sciences and Education Research, 3(3), 772-782.

accordance with organizational setting (Original item: "Participates in activities and or discussions in the class") Cronbach alpha value of the scale is .89 .

\section{Results}

\subsection{Analyses for the scales}

For both scales, exploratory Factor Analysis was done by using Principal Component Method with varimax rotation.

\subsubsection{Factor and reliability analyses for FMI}

Factor analysis for 14-item FMI extracted two factors explaining 51.38 percent of the variance $(\mathrm{KMO}=.87$, Bartlett Sphericity Test $=1055.497, p<.001)$. One item (item 13) is excluded from the analysis because of the low factor loading. The first factor named as nonjudgmental acceptance and is composed of seven items. The second factor referred as commitment to experience, consists of six items (see Table 1). Walach et al. (2006) found four factors in the long version of FMI but suggest that it is better to use mindfulness as a one-dimensional construct in both short and long versions. By using confirmatory factor analysis, Kohl et al. (2009) compared two dimensional (named as presence and acceptance) and one-dimensional solution and inferred that the former fits better to the data and the latter is sufficient for practical applications. Hence, the two-dimensional structure obtained in this study is consistent with the finding of Kohl et al. (2009).

Table 1. Factor and reliability analyses for FMI

\begin{tabular}{|c|c|c|}
\hline Item no & Mindfulness & Factor Loading \\
\hline & $\begin{array}{l}\text { Factor name: Nonjudgmental acceptance }(\text { Explained variance }=28.21 ; \alpha \\
=.85)\end{array}$ & \\
\hline $\mathrm{I} 12$ & $\begin{array}{l}\text { I experience moments of inner peace and ease, even when things get hectic } \\
\text { and stressful. }\end{array}$ & .80 \\
\hline I9 & I am friendly to myself when things go wrong. & .78 \\
\hline $\mathrm{I} 10$ & I watch my feelings without getting lost in them. & .77 \\
\hline I11 & In difficult situations, I can pause without immediately reacting. & .75 \\
\hline I14 & I am able to smile when I notice how I sometimes make life difficult. & .72 \\
\hline I6 & I see my mistakes and difficulties without judging them. & .50 \\
\hline \multirow[t]{2}{*}{ I8 } & I accept unpleasant experiences. & .41 \\
\hline & $\begin{array}{l}\text { Factor name: Commitment to current experience }(\text { Explained variance }= \\
23.17 ; \alpha=.75)\end{array}$ & \\
\hline I7 & I feel connected to my experience in the here-and-now. & .70 \\
\hline I5 & I pay attention to what's behind my actions. & .65 \\
\hline I1 & I am open to the experience of the present moment. & .65 \\
\hline I2 & I sense my body, whether eating, cooking, cleaning or talking. & .64 \\
\hline I3 & $\begin{array}{l}\text { When I notice an absence of mind, I gently return to the experience of the } \\
\text { here and now. }\end{array}$ & .63 \\
\hline \multirow[t]{2}{*}{ I4 } & I am able to appreciate myself. & .62 \\
\hline & KMO $=.87 ;$ Bartlett Test Chi Square $=1055.497 \mathrm{df}=78 p<.001$ & \\
\hline
\end{tabular}


Kalafatoğlu, Y., Turgut, T. (2017). Another benefit of mindfulness: Ethical behaviour. International Journal of Social Sciences and Education Research, 3(3), 772-782.

\subsubsection{Factor and reliability analyses for EBRS}

After excluding item 11 as it decreases the reliability of the scale three factors were inferred explaining 60.03 percent of the variance $(\mathrm{KMO}=.90$, Bartlett Sphericity Test $=1440.701, p<$ $.001)$. The first factor named as moral trait is composed of four items. The second factor named as concern for others, consists of four items. The third factor, participation and cooperation has six items (see Table 2).

Table 2. Factor analysis and reliability results of ethical behaviour scale

\begin{tabular}{|c|c|c|}
\hline Item no & Ethical Behaviour & Factor Loading \\
\hline & Factor name: Moral trait $($ Explained variance $=20.94 ; \alpha=.85)$ & \\
\hline $\mathrm{I} 3$ & Verbalizes judgments on rightness or wrongness of certain behaviours & .82 \\
\hline I4 & Will act in defense of a friend & .79 \\
\hline $\mathrm{I} 2$ & Is trustworthy; has not been known to cheat & .72 \\
\hline \multirow[t]{2}{*}{ I1 } & Speaks out for fairness for others as well as self & .68 \\
\hline & Factor name: Concern for others $($ Explained variance $=20.45 ; \alpha=.77)$ & \\
\hline I14 & Treats others with respect & .80 \\
\hline $\mathrm{I} 15$ & Verbalizes logical reasoning beyond a completely selfish point of view & .75 \\
\hline I6 & Understands or shows an effort to understand & .72 \\
\hline \multirow[t]{2}{*}{ I5 } & Can be depended on to be honest & .60 \\
\hline & $\begin{array}{l}\text { Factor name: Participation and cooperation }(\text { Explained variance }= \\
18.64 ; \alpha=.80)\end{array}$ & \\
\hline I13 & Can be counted on to cooperate in small group activities & .73 \\
\hline I8 & Verbalizes loyalty to a group or institution & .71 \\
\hline $\mathrm{I} 10$ & Participates in activities and or discussions in the workplace & .71 \\
\hline I9 & Will admit a mistake & .54 \\
\hline $\mathrm{I} 12$ & Shows a genuine concern for the welfare of fellow humans & .50 \\
\hline \multirow[t]{2}{*}{ I7 } & Is willing to help someone in need whether good friend or not & .40 \\
\hline & KMO $=.901 ;$ Bartlett Test Chi Square $=1440.701 \mathrm{df}=91 p<.001$ & \\
\hline
\end{tabular}

\subsection{Descriptive statistics and correlations among study variables}

Means, standard deviations and Pearson correlation coefficients can be seen in Table 3. Results indicate that each dimension of mindfulness is significantly related with dimensions of ethical behaviour. The most powerful correlation is between commitment to experience and concern for others $(r=.50)$ whereas the least powerful correlation is between nonjudgmental acceptance and moral trait $(r=.21)$. Moreover, the relationships of commitment to experience with dimensions of ethical behaviour are stronger than those of nonjudgmental acceptance.

In this study, it was seen that dimensions of each variable are also significantly related to each other. Since the strongest relation is lower than $.70(r=.64)$, no multicollinearity risk was suspected. Demographic variables have weak correlations with ethical behaviour. Education is significantly related with moral trait and concern for others. Total tenure is significantly related with moral trait. 
Kalafatoğlu, Y., Turgut, T. (2017). Another benefit of mindfulness: Ethical behaviour. International Journal of Social Sciences and Education Research, 3(3), 772-782.

Table 3. Correlations among the variables

\begin{tabular}{lllllllll}
\hline VARIABLES & $\mathbf{M}$ & SD & $\mathbf{2}$ & $\mathbf{3}$ & $\mathbf{4}$ & $\mathbf{5}$ & $\mathbf{6}$ & $\mathbf{7}$ \\
\hline 1. Education & & & .03 & .10 & .01 & $.18^{* *}$ & .07 & $.14^{*}$ \\
2.Total tenure & 7.29 & 6.35 & 1 & .02 & .02 & $.16^{*}$ & .08 & .09 \\
3. C.Experience & 4.59 & 0.72 & & 1 & $.53^{* *}$ & $.44^{* *}$ & $.48^{* *}$ & $.50^{* *}$ \\
4. N.Acceptance & 3.80 & 0.87 & & & 1 & $.21^{* *}$ & $.34^{* *}$ & $.27 * *$ \\
5.Moral trait & 4.87 & 0.82 & & & & 1 & $.62 * *$ & $.64 * *$ \\
6. Participation & 4.59 & 0.77 & & & & & 1 & $.63^{* *}$ \\
$\begin{array}{l}\text { 7. Concern for } \\
\text { others }\end{array}$ & 5.19 & 0.67 & & & & & 1 \\
$\begin{array}{l}\text { Note: } \text { Education is involved in the analysis as a dummy variable. } 0=\text { Bachelor's degree, } 1 \text { = Master degree. } \\
* p<0,05, * * p<0,01\end{array}$
\end{tabular}

\subsection{Hypothesis testing}

For testing the hypothesis, the contribution of mindfulness on ethical behaviour was analysed with simple regression analysis. Results indicate that mindfulness has significant and positive contribution on moral trait (Adjusted $R^{2}=.13, F=36.68, p<.001$ ), participation/cooperation (Adjusted $R^{2}=.20, F=59.21, p<.001$ ) and concern for others (Adjusted $R^{2}=.18, F=51.09, p$ $<.001)$. These results support Hypothesis 1.

Table 4. Simple regression analysis for mindfulness and ethical behaviour dimensions

\begin{tabular}{rccc}
\hline & Moral trait & $\begin{array}{c}\text { Ethical Behaviour } \\
\text { Participation/cooperation }\end{array}$ & $\begin{array}{c}\text { Concern for } \\
\text { others }\end{array}$ \\
\hline FMI & $\beta=.37 * * *$ & $\beta=.46^{* * *}$ & $\beta=.43^{* * *}$ \\
$\boldsymbol{R}$ & .37 & .46 & .43 \\
$\boldsymbol{R}^{2}$ & .14 & .21 & .18 \\
Adjusted $\boldsymbol{R}^{2}$ & .13 & .20 & .18 \\
$\boldsymbol{F}$ & $36.68^{* * *}$ & $59.21 * * *$ & $51.09 * * *$ \\
\hline${ }^{*} p<.05 ;{ }^{* *} p<.01 ; * * p<.001$ & &
\end{tabular}

Then, multiple regression analysis was applied with entering the dimensions of mindfulness as independent variable. For the threat of multicollinearity, VIF values were examined and it was seen that VIF values are around 1 . Therefore, multicollinearity assumption was met. Results show that only commitment to experience has significant contribution to moral trait (Adjusted $R^{2}=.20$, $F=28.81, p<.001$ ) participation and cooperation (Adjusted $R^{2}=.23, F=35.45, p<.001$ ) and concern for others (Adjusted $R^{2}=.26, F=40.67, p<.001$ ). The contribution of commitment to experience on concern for others $(\beta=.51, p<.001)$ is higher than moral trait $(\beta=.45, p<.001)$ and participation and cooperation $(\beta=.41, p<.001)$. 
Kalafatoğlu, Y., Turgut, T. (2017). Another benefit of mindfulness: Ethical behaviour. International Journal of Social Sciences and Education Research, 3(3), 772-782.

Table 5. Multiple Regression analysis for dimensions of both mindfulness and the ethical behaviour

\begin{tabular}{|c|c|c|c|}
\hline & \multicolumn{3}{|c|}{ Ethical Behaviour } \\
\hline & Moral trait & $\begin{array}{c}\text { Participation } \\
\text { and cooperation }\end{array}$ & $\begin{array}{c}\text { Concern for } \\
\text { others }\end{array}$ \\
\hline $\begin{array}{c}\text { Commitment to } \\
\text { experience }\end{array}$ & $\beta=.45 * * *$ & $\beta=.41^{* * *}$ & $\beta=.51 * * *$ \\
\hline $\begin{array}{c}\text { Nonjudgmental ac- } \\
\text { ceptance }\end{array}$ & $\beta=.01$ & $\beta=.13$ & $\beta=.01$ \\
\hline $\boldsymbol{R}$ & .45 & .49 & .51 \\
\hline $\boldsymbol{R}^{2}$ & .20 & .24 & .26 \\
\hline Adjusted $R^{2}$ & .20 & .23 & .26 \\
\hline $\boldsymbol{F}$ & $28.81 * * *$ & $35.45 * * *$ & $40.67 * * *$ \\
\hline
\end{tabular}

\section{Discussion}

The aim of this study is to examine the association between mindfulness and ethical behaviour. Results indicate that mindfulness explains variance in ethical behaviour; the more mindful the individuals, the more they behave ethically. The relationship between mindfulness and ethical behaviour can be explained with self-regulation theory and moral emotions. Self-regulation occurs when one has standards, monitor his/her actions and operate accordingly (Baumeister, Heatherton \& Tice, 1994; Carver \& Scheier, 1982) and it is seen as the strongest path for being a successful and an agreeable person (Baumeister et al., 1994). It is a cognitive process in which mindful individuals may be better at. Moral emotions may be stimulated as a result of being mindful. We think that the link between mindfulness and ethical behaviour occurs as a combined effect of self-regulation and stimulation of moral emotions.

Self-regulation is a process that is controlled by the individual itself to outrival an impulse's natural consequence rather than hindering the impulse from taking place (Baumeister \& Heatherhon, 1996). Three components of self-regulation were described within a feedback-loop framework by Carver and Scheier (1982). The first component is standards. One must have standards which refer to goals that are pursued. Then monitoring should occur, one watches his/her actions and states. Lastly, operating works; when the desired end isn't achieved, the individual acts to change the present situation (Baumeister et al., 1994). An overweight person who is on a diet, a student who work hard for pursuit of an academic degree and a partner who tries to manage his/her romantic relationship during a conflict all have a common attribute. They regulate their behaviours and avoid desired impulses like eating snack, watching favourite TV series or misbehave. Self-regulation failure results with not only individual problems like obesity, defailment at school or partner abuse but also as Bauemister et al. claimed (1994) it is the main cause of destructive, illegal and antisocial behaviour. In our opinions, mindful individuals are expected to be better at self-regulation as they behave coherently to their moral standards, monitor their feelings and actions and accommodate their behaviours. Mindful individuals may reveal suitable behaviours that match with the context rather than acting like an automatic pilot or pursuing to gratify immediate desires.

Regression analysis results for each dimension of mindfulness and ethical behaviour indicate that commitment to experience is associated with all ethical behaviour dimensions. When the 
Kalafatoğlu, Y., Turgut, T. (2017). Another benefit of mindfulness: Ethical behaviour. International Journal of Social Sciences and Education Research, 3(3), 772-782.

correlation analysis is examined, both nonjudgmental acceptance and commitment to current experience are found to be related with ethical behaviour dimensions (see Table 3). However, when two dimensions of mindfulness are entered with ethical behaviour dimensions into the regression equation, the contribution of commitment to experience become prominent and the contribution of nonjudgmental acceptance becomes weaker. Thus, the increment on ethical behaviour should be investigated particularly on the commitment to experience concept.

Previous studies indicate that mindfulness is associated with self-control (Brown, Ryan, \& Creswell, 2007; Lakey et al., 2007; Wittman et al., 2014). Although self-control and self-regulation are similar concepts and self-control is a concept used in self-regulation framework, the former refers to inhibiting strong impulses but the latter involves decreasing the intense consequences of that impulse with an effective management (Schanker, 2016). Self-control is called moral muscle as it determines moral acts, but just like muscle, when it is surcharged, it may lose its strength (Baumeister \& Exline, 1999; Mead et al., 2009). Mindful individuals may be better in self-control. However, commitment to current experience dimension may be more related with self-regulation as it involves a cognitive aspect which includes attentiveness and awareness about oneself and the present situation. On the other hand, nonjudgmental acceptance involves nonreactance and acceptance which may be more related with self-control. We think that the prominent effect of commitment to experience on ethical behaviour is related with successful self-regulation as the individual internalizes his/her actions rather than a mere control.

Also when one has higher awareness and experience to the current situation, this may stimulate moral emotions which refer to "those emotions that are linked to the interests or welfare either of society as a whole or at least of the persons other than the judge or agent" (Haidt, 2003, p.853). Such emotions which may motivate one to act morally as compassion and love (Cova, Deonna, \& Sander, 2015), may be stimulated with mindful awareness.

Education is positively related with moral trait and concern for others. Previous studies have conflicting results for the relationship between education and ethical judgments (Chiu, 2003, Swaidan et al., 2003). Pan and Spark (2012)'s meta-analysis reveal that those who have more education have less strict ethical judgment. Although our results may seem incompatible with this meta-analysis, actually it isn't. Pan and Spark (2012) suggest that education may trigger individuals to interpret events with a broader perspective which matches with Kohlberg (1981)'s moral development theory. Individuals with more education may behave more ethically as our study shows, but at the same time their judgment may be less strict than the others. In this study, participants education level mainly differ between bachelor's and master degree. Future studies may analyze whether the education gap (Primary school vs master degree) create a stronger difference in terms of ethical behaviour.

One of the core aspects of mindfulness is an increased awareness of being in here and now rather than live like a mindless automatic pilot. Mindfulness contains to experience the current situation directly, but not ruminating about its implications or any other meanings (Teasdale et al., 1995). Therefore, when a mindful employee goes through a situation, as she/he is aware of the requirements of the present moment, she/he may probably respond ethically. Since mindful individuals have less ego concerns and selfish desires, positive association between mindfulness and moral trait aspect is expected. However, the absence of the relationship between nonjudgmental acceptance and ethical behaviour dimensions may direct future studies. Utilization of other mindfulness scales, measuring the mediating effects of emotions and experimental manipulations 
Kalafatoğlu, Y., Turgut, T. (2017). Another benefit of mindfulness: Ethical behaviour. International Journal of Social Sciences and Education Research, 3(3), 772-782.

may draw a more thorough picture. This study is cross-sectional therefore no causality can be drawn.

\section{Implications}

Mindfulness requires being conscious about the current situation, attentive to the environmental cues and having acceptance to the imperfections that life brings which may be either one's own failures or other's flaws. Previous research suggests that promotion of eudemonic living which is cultivated by mindfulness result with more social responsible actions (Ryan \& Huta, \& Deci, 2008). This study contributes to the literature as it reveals the benefits of mindfulness on ethical behaviour in workplace. Also, this study appears as a criticism to the exploitation of mindfulness concept. We claim that researchers should protect the essence of the concept which involves a long-lasting philosophy directing individuals for universal welfare. Removing the ethical aspects of mindfulness and utilize it for the sake of shallow purposes may result with "the potential for something priceless to be lost" (Williams \& Kabat-Zinn, 2011, p.4).

\section{Practical suggestions}

The results of this research reveal that commitment to experience, a dimension of mindfulness, is a beneficial concept for organizations as it improves ethical behaviour. Mindfulness may be critically important for work contexts where sensitive treatment and pro-social behaviour become crucial such as health or education sector. Therefore, HR staff may combine mindfulness test into their personnel selection tools. As mindfulness is a state as well as a trait, organizations may provide mindfulness training to their staff. Meditation and yoga are popular ways to trigger state mindfulness. However, as Troyer (2011) revealed religion/spiritual discipline and martial arts may also be alternatives to increase the level of consciousness.

\section{References}

Allen, T. D., \& Kiburz, K. M. (2012). Trait mindfulness and work-family balance among working parents: The mediating effects of vitality and sleep quality. Journal of Vocational Behaviour, 80, 372-379.

Baumeister, R. F., \& Exline, J. J. (1999). Virtue, personality and social relations: Self-control as the moral muscle. Journal of Personality, 67, 1165-1194.

Baumeister R. F., \& Heatherton T. F. (1996). Self-regulation failure: An overview. Psychological Inquiry, $7,1-15$.

Baumeister, R. F., Heatherton, T. F., \& Tice, D. M. (1994). Losing control: How and why people fail at self-regulation. San Diego, CA: Academic Press.

Baumeister, R. F., \& Vohs, K. (2007). Self-regulation, ego depletion, and motivation. Social and Personality Psychology Compass, 1, 1-14.

Bishop, S. R., Lau, M., Shapiro, S., Carlson, L., Anderson, N. D., Segal, Z. V., Abbey, S., Speca, M., Velting, D., \& Devins, G.(2004). Mindfulness: A proposed operational definition. Clinical Psychology: Science and Practice, 11(3), 230-241.

Blasi, A. (1980). Bridging moral cognition and moral action: A critical review of literature. Psychological Bulletin, 88, 1-45.

Brown, K. W., \& Ryan, R. M. (2003).The benefits of being present: Mindfulness and its role of psychological well-being. Journal of Personality and Social Psychology, 84, 822-848. 
Kalafatoğlu, Y., Turgut, T. (2017). Another benefit of mindfulness: Ethical behaviour. International Journal of Social Sciences and Education Research, 3(3), 772-782.

Brown, K. W., Ryan, R. M., \& Creswell, J. D. (2007). Mindfulness: Theoretical foundations and evidence for its salutary effects. Psychological Inquiry, 18(4), 211-237.

Buchheld, N., Grossman, P., \& Walach, H. (2001). Measuring mindfulness in insight meditation and meditation - based psychotherapy: The development of Freiburg Mindfulness Inventory (FMI). Journal for Meditation and Meditation Research, 1, 11-34.

Carver, C. S., \& Scheier, M. F. (1982). Control theory: A useful conceptual framework for personalitysocial, clinical, and health psychology. Psychological Bulletin, 92(1), 111-135. DOI: 10.1037/00332909.92.1.111

Chiu R. K. (2003). Ethical judgment and whistleblowing intention: examining the moderating role of locus of control. Journal of Business Ethics, 43, 65-74.

Cova, F., Deonna, J., \& Sander, D. (2015). Introduction: moral emotions. Topoi, 34, 397-400.

Haidt, J. (2003). The moral emotions. In Davidson J. R. Scherer, K. R., Goldsmith, H. H. (Eds). Handbook of Affective Sciences. Oxford University Press, Oxford

Hill, G., \& Swanson, H. L. (1985). Construct validity and reliability of the ethical behaviour scale. Educational and Pscyhological Measurement, 45, 285-292.

Hogan, R. (1973). Moral conduct and moral character: A psychological perspective. Psychological Bulletin, 79, 217-232.

Hollis-Walker, L., \& Colosimo, K. (2011). Mindfulness, self-compassion and happiness in non-mediators: A theoretical and empirical examination. Personality and Individual Differences, 50, 222-227.

Hülsheger, U. R., Alberts, H. J. E. M., Feinholdt, A., \& Lang, J. W. B. (2013). Benefits of mindfulness at work: The role of mindfulness in emotion regulation, emotional exhaustion, and job satisfaction. Journal of Applied Psychology, 98, 310-325.

Hülsheger, U. R., Lang, J. W. B., Depenbrock, F., Fehrmann, C., Zijlstra, F., \& Alberts, H. J. E. M. (2014). The power of presence: The role of mindfulness at work for daily levels and change trajectories of psychological detachment and sleep quality. Journal of Applied Psychology, 99, 1113-1128.

Hyland, T. (2015). On the contemporary applications of mindfulness: some implications for education. Journal of Philosophy of Education, 49(2).

Jankowski, T., \& Holas, P. (2014). Metacognitive model of mindfulness. Consciousness and Cognition, $28,64-80$.

Kabat-Zinn, J. (1990). Full catastrophe living: Using the wisdom of your body and mind to face stress, pain and illness. New York: Delacorte.

Kabat-Zinn, J. (2005). Coming to our senses: Healing ourselves and the world through mindfulness. New York: Hyperion.

Kapıkıran, N. A. (2007). Üniversite öğrencilerinde ahlaki davranışın empatik eğilim ve kendini ayarlama açısından incelenmesi. Türk Psikolojik Danışma ve Rehberlik Dergisi, 3(28).

Kohlberg, L. (1981). The philosophy of moral development: Moral stages and the idea of justice. San Fran cisco: Harper \& Row.

Lakey, C. E., Campbell, W. K., Brown, K. W., \& Woodie, A. S. (2007). Dispositional mindfulness as a pr edictor of the severity of gambling outcomes. Personality and Individual Differences, 43, 1698-1710.

Mead, N. L., Baumeister, R. F., Gino, F., Schweitzer, M. E., \& Ariely, D. (2009). Too tired to tell the truth: Self-control resource depletion and dishonesty. Journal of Experimental Social Psychology, 45, 594597. 
Kalafatoğlu, Y., Turgut, T. (2017). Another benefit of mindfulness: Ethical behaviour. International Journal of Social Sciences and Education Research, 3(3), 772-782.

Pan, Y., \& Sparks, J. R. (2012). Predictors, consequence, and measurement of ethical judgments: Review and meta-analysis. Journal of Business Research, 65, 84-91.

Reb, J., Narayanan, J., \& Ho, Z. W. (2015). Mindfulness at work: Antecedents and consequences of employee awareness and absent-mindedness. Mindfulness, 6(1), 111-122.

Ruedy, N. E., \& Schweitzer, M. E. (2010). In the moment: The effect of mindfulness on ethical decision making. Journal of Business Ethics, 95(1), 73-87.

Ryan, R. M., Huta, V., \& Deci, E. L. (2008). Living well: A self-determination theory perspective on Eudaimonia. Journal of Happiness Studies, 9, 139-170.

Schanker, S. (2016). Self-reg: Self-regulation vs self-control. Retrieved in 22/04/2017 from https://www.psychologytoday.com/blog/self-reg/201607/self-reg-self-regulation-vs-self-control.

Shapiro, S. L, Jazaieri, H., \& Goldin, P. R. (2012): Mindfulness-based stress reduction effects on moral reasoning and decision making. The Journal of Positive Psychology, 1-12, DOI:10.1080/17439760.2012.723732.

Swaidan Z., Vitell S. J., \& Rawwas M.Y.A. (2003). Consumer ethics: determinants of ethical beliefs of African Americans. Journal of Business Ethics, 46, 175-86.

Teasdale, J. D., Segal Z., \& Williams J. M. G. (1995). How does cognitive therapy prevent depressive relapse and why should attentional control (mindfulness) training help. Behaviour Research and Therapy, 33, 25-39.

Troyer, J. A. (2011). Level of consciousness: Reframing our understanding of individual differences in learning. International Conference on Education and Educational Psychology, 12, 290-299.

Vallabh, P., \& Singhal, M. (2014). Buddhism and decision-making at individual, group and organizational levels. Journal of Management Development, 33, 8-9.

Walach, H., Buchheld, N., Buttenmuller, V., Kleinknecht, N., \& Schmidt, S. (2006). Measuring mindfulness-The Freiburg Mindfulness Inventory (FMI). Personality and Individual Differences, 40, 15431555

Williams, M., \& Kabat-Zinn, J. (2011). Mindfulness: Diverse perspectives on its meanings, origins and multiple applications at the intersection of science and dharma. Contemporary Buddhism, 12(1), 1-18.

Wittmann M., Peter J., Gutina O., Otten S., Kohls N., Meissner K. (2014). Individual differences in selfattributed mindfulness levels are related to the experience of time and cognitive self-control. Personality and Individual Differences 64 41-45 10.1016/j.paid.2014.02.011.

Yam, K. C., Chen, X. P., \& Reynolds, S. J. (2014). Ego depletion and its paradoxical effects on ethical decision making. Organizational Behavior and Human Decision Processes, 124, 204-214.

Zeidan, F., Johnson, S. K., Diamond, B. J., David, Z., \& Goolkasian, P. (2010). Mindfulness Meditation Improved Cognition: Evidence of Brief Mental Training. Consciousness and Cognition, 19, 597-605.

Zhang, J., \& Wu, C. (2014). The influence of dispositional mindfulness on safety behaviours: A dual process perspective. Accident Analysis and Prevention, 70, 24-32. 